\title{
Preoperative White Blood Cell Count and Risk of 30-Day Readmission after Cardiac Surgery
}

\author{
Jeremiah R. Brown, ${ }^{1}$ R. Clive Landis, ${ }^{2}$ Kristine Chaisson, ${ }^{3}$ Cathy S. Ross, ${ }^{1}$ \\ Lawrence J. Dacey, ${ }^{4}$ Richard A. Boss Jr., ${ }^{4}$ Robert E. Helm, ${ }^{5}$ Susan R. Horton, ${ }^{6}$ \\ Patricia Hofmaster, ${ }^{7}$ Cheryl Jones, ${ }^{8}$ Helen Desaulniers, ${ }^{9}$ Benjamin M. Westbrook, \\ Dennis Duquette, ${ }^{5}$ Kelly LeBlond, ${ }^{6}$ Reed D. Quinn, ${ }^{8}$ Patrick C. Magnus, ${ }^{1}$ \\ David J. Malenka, ${ }^{1}$ and Anthony W. DiScipio ${ }^{4}$ \\ ${ }^{1}$ The Dartmouth Institute for Health Policy and Clinical Practice, Departments of Medicine Section of Cardiology and Community and \\ Family Medicine and Dartmouth-Hitchcock Medical Center, Lebanon, NH 03756, USA \\ ${ }^{2}$ Edmund Cohen Laboratory for Vascular Research, The University of the West Indies, Bridgetown, Barbados \\ ${ }^{3}$ Department of Surgery, Concord Hospital, Concord, NH, USA \\ ${ }^{4}$ Department of Surgery, Dartmouth-Hitchcock Medical Center, Lebanon, NH 03756, USA \\ ${ }^{5}$ Department of Surgery, Portsmouth Regional Hospital, Portsmouth, NH, USA \\ ${ }^{6}$ Department of Surgery, Central Maine Medical Center, Lewiston, ME, USA \\ ${ }^{7}$ Department of Surgery, Eastern Maine Medical Center, Bangor, ME, USA \\ ${ }^{8}$ Department of Surgery, Maine Medical Center, Portland, ME, USA \\ ${ }^{9}$ Department of Surgery, Catholic Medical Center, Manchester, NH, USA
}

Correspondence should be addressed to Jeremiah R. Brown; jbrown@dartmouth.edu

Received 24 April 2013; Revised 26 June 2013; Accepted 26 June 2013

Academic Editor: Paulo Roberto Barbosa Evora

Copyright ( $) 2013$ Jeremiah R. Brown et al. This is an open access article distributed under the Creative Commons Attribution License, which permits unrestricted use, distribution, and reproduction in any medium, provided the original work is properly cited.

Approximately 1 in 5 patients undergoing cardiac surgery are readmitted within 30 days of discharge. Among the primary causes of readmission are infection and disease states susceptible to the inflammatory cascade, such as diabetes, chronic obstructive pulmonary disease, and gastrointestinal complications. Currently, it is not known if a patient's baseline inflammatory state measured by crude white blood cell (WBC) counts could predict 30-day readmission. We collected data from 2,176 consecutive patients who underwent cardiac surgery at seven hospitals. Patient readmission data was abstracted from each hospital. The independent association with preoperative WBC count was determined using logistic regression. There were 259 patients readmitted within 30 days, with a median time of readmission of 9 days (IQR 4-16). Patients with elevated WBC count at baseline $(10,000-12,000$ and $>12,000 \mathrm{~mm}^{3}$ ) had higher 30 -day readmission than those with lower levels of WBC count prior to surgery ( $15 \%$ and $18 \%$ compared to $10 \%-12 \%, P=0.037)$. Adjusted odds ratios were $1.42(0.86,2.34)$ for WBC counts $10,000-12,000$ and $1.81(1.03,3.17)$ for WBC count $>12,000$. We conclude that WBC count measured prior to cardiac surgery as a measure of the patient's inflammatory state could aid clinicians and continuity of care management teams in identifying patients at heightened risk of 30-day readmission after discharge from cardiac surgery.

\section{Introduction}

Approximately one in every five hospitalized patients is readmitted within 30 days [1]. Currently, two-thirds of US hospitals have reimbursement penalties for higher than expected 30-day readmission rates from the Center for Medicaid and
Medicare Services $[2,3]$. It is expected that similar penalties will be extended to other procedures and diagnoses including cardiac surgery. In preparation for the expansion of the penalty system in the USA and to improve prediction of patients at high risk of postdischarge complications leading to readmissions or premature death, risk factors must be 
identified early in the hospital course to align the best possible quality and continuity of care.

Currently, a validated risk model for predicting readmissions after cardiac surgery is not available and few risk factors for readmission are known. Recent evidence from California reported an association between infection and higher rates of 30-day readmission after cardiac surgery [4]. However, identification of infection after discharge without routine monitoring of a postcardiac surgical patient is problematic. What is needed is for clinical care teams to identify patients at high risk of infection before cardiac surgery to determine readiness and safety for the patient to undergo surgery. A common marker of inflammation is white blood cell (WBC) count, routinely measured prior to cardiac surgery. WBC count provides a broad measure of inflammation status, whether as a result of infection or proinflammatory disease states such as diabetes, COPD, or hemodialysis [5-8]. Elevated WBC count is reported as a component of the systemic inflammatory response syndrome (SIRS) to sepsis and is endorsed as a marker for reporting the systemic inflammatory response to cardiopulmonary bypass $[9,10]$. In addition, current evidence has shown that preoperative WBC count is predictive of inhospital mortality and stroke [11] and major bleeding [12] after coronary artery bypass graft surgery and associated with complications in other endovascular and thoracic procedures $[13,14]$, suggesting that preoperative WBC count may aid clinical care teams in risk-stratifying patients prior to surgery. However, it is not known if a patient's baseline inflammatory state measured by crude WBC count could predict 30 -day readmission. Therefore, we sought to evaluate whether preoperative WBC count was associated with 30 -day readmissions after cardiac surgery.

\section{Methods}

Patients undergoing coronary artery bypass graft (CABG) surgery and/or valve surgery within the Northern New England Cardiovascular Disease Study Group (NNE) between July 2008 and December 2010 were enrolled in the cohort. A total of 2,209 consecutive patients were included along with 268 readmissions to the hospital performing the index cardiac surgery. Twelve patients were excluded due to missing white blood cell counts and twenty-one for incomplete data, leaving a total of 2,176 patients and 259 readmissions occurring within 30 days of discharge from the index cardiac surgery admission. All institutional review boards for each center reviewed and approved the data collection for the NNE registry and supplementary data collection for readmissions.

The NNE is a voluntary regional consortium of physicians, allied health professionals, research scientists, and hospital administrators from institutions in Maine, New Hampshire, and Vermont that support coronary revascularization and open-heart surgery. The goal of the consortium is to foster continuous improvement in the quality, safety, and effectiveness of care for patients with cardiovascular disease through the analysis of process and outcomes data with timely feedback to the health care professionals providing these services. All the hospitals providing open-heart surgery in this region contribute data on consecutive cases with
TABLE 1: Characteristics of patients with or without 30-day readmission.

\begin{tabular}{|c|c|c|c|}
\hline \multirow{2}{*}{ Characteristic } & \multicolumn{3}{|c|}{ 30-day readmission } \\
\hline & No & Yes & $P$ value \\
\hline Number of patients $(2,176)$ & 1,917 & 259 & \\
\hline \multicolumn{4}{|l|}{ Demographics } \\
\hline Age & $66.2 \pm 11.2$ & $66.4 \pm 11.5$ & 0.740 \\
\hline Female & 28.5 & 32.8 & 0.154 \\
\hline BMI & $29.6 \pm 5.9$ & $29.8 \pm 6.5$ & 0.585 \\
\hline \multicolumn{4}{|l|}{ Comorbidities } \\
\hline Type 2 diabetes mellitus & 31.5 & 37.1 & 0.070 \\
\hline Vascular disease & 27.3 & 30.9 & 0.224 \\
\hline COPD & 15.6 & 20.5 & 0.043 \\
\hline History of dialysis & 2.4 & 5.0 & 0.015 \\
\hline Smoking & 21.4 & 22.4 & 0.726 \\
\hline \multicolumn{4}{|l|}{ Cardiac history } \\
\hline Recent MI & 17.3 & 13.1 & 0.091 \\
\hline $\mathrm{CHF}$ & 19.9 & 25.1 & 0.051 \\
\hline Prior $\mathrm{CABG}$ & 3.9 & 2.7 & 0.337 \\
\hline Prior valve & 1.5 & 1.9 & 0.611 \\
\hline Prior PCI & 18.2 & 17.4 & 0.760 \\
\hline NYHA Class IV & 15.6 & 15.4 & 0.949 \\
\hline \multicolumn{4}{|c|}{ Cardiac anatomy and function } \\
\hline Left main disease $\geq 50 \%$ & 28.8 & 20.9 & 0.007 \\
\hline Single-vessel disease & 33.5 & 42.6 & 0.002 \\
\hline Two-vessel disease & 28.5 & 30.2 & \\
\hline Three-vessel disease & 38.1 & 27.3 & \\
\hline \multicolumn{4}{|l|}{ Ejection fraction } \\
\hline$<40 \%$ & 11.3 & 12.3 & 0.894 \\
\hline $40 \%-59 \%$ & 12.6 & 11.1 & \\
\hline $50 \%-59 \%$ & 24.3 & 24.2 & \\
\hline$\geq 60 \%$ & 51.7 & 52.4 & \\
\hline \multicolumn{4}{|l|}{$\begin{array}{l}\text { White blood cell count (in } \\
1,000 \text { 's, } \mathrm{mm}^{3} \text { ) }\end{array}$} \\
\hline$<6.0$ & 19.9 & 19.7 & 0.037 \\
\hline $6.0-7.9$ & 39.2 & 35.9 & \\
\hline $8.0-9.9$ & 25.3 & 21.6 & \\
\hline $10.0-12.0$ & 9.9 & 13.1 & \\
\hline$>12.0$ & 5.6 & 9.7 & \\
\hline
\end{tabular}

COPD: chronic obstructive pulmonary disease; MI: myocardial infarction; CHF: congestive heart failure; CABG: coronary artery bypass graft surgery; PCI: percutaneous coronary intervention; WBC: white blood cell; eGFR: estimated glomerular filtration rate.

validation of procedure numbers and mortality performed every two years. The registry collects data on patient characteristics, procedural indication, priority, and process, and inhospital outcomes (see http://www.nnecdsg.org/ for the data forms and publically available data).

WBC count was defined as the last preoperative measurement of WBC taken prior to procedure, was collected by data abstractor at each center. Categories of WBC counts were 
TABle 2: Procedural characteristics and outcomes of patients with or without 30-day readmission.

\begin{tabular}{|c|c|c|c|}
\hline \multirow{2}{*}{ Characteristic } & \multicolumn{3}{|c|}{ 30-day readmission } \\
\hline & No & Yes & $P$ value \\
\hline \multicolumn{4}{|l|}{ Procedural characteristics } \\
\hline \multicolumn{4}{|l|}{ Priority } \\
\hline Emergent & 5.3 & 6.6 & 0.534 \\
\hline Urgent & 50.9 & 47.9 & \\
\hline Elective & 43.9 & 45.6 & \\
\hline \multicolumn{4}{|l|}{ Procedure } \\
\hline CABG & 60.7 & 51.0 & 0.007 \\
\hline Valve & 22.4 & 30.1 & \\
\hline CABG/valve & 17.0 & 18.9 & \\
\hline On-pump surgery & 90.3 & 95.8 & 0.004 \\
\hline Nadir hematocrit $<20$ on bypass & 15.0 & 20.5 & 0.029 \\
\hline Cardiopulmonary bypass time (min) & $119.7 \pm 53.7$ & $122.9 \pm 56.5$ & 0.393 \\
\hline Time to initial extubation (min) & $17.3 \pm 65.2$ & $17.6 \pm 35.1$ & 0.951 \\
\hline Intraoperative myocardial infarction & 2.4 & 2.7 & 0.725 \\
\hline Return to bypass & 4.2 & 4.6 & 0.730 \\
\hline \multicolumn{4}{|l|}{ Management } \\
\hline \multicolumn{4}{|l|}{$\mathrm{RBC}$ transfusions } \\
\hline None & 67.6 & 58.7 & 0.001 \\
\hline One & 8.9 & 10.0 & \\
\hline Two & 10.3 & 9.3 & \\
\hline Three or more & 13.2 & 22.0 & \\
\hline \multicolumn{4}{|l|}{ Use of 1 or more inotropes } \\
\hline Arrive to ICU & 43.9 & 44.0 & 0.965 \\
\hline After 4 hours & 37.2 & 44.0 & 0.034 \\
\hline After 48 hours & 11.3 & 15.1 & 0.080 \\
\hline \multicolumn{4}{|l|}{ Adverse outcomes } \\
\hline Low-cardiac output failure & 8.0 & 10.0 & 0.272 \\
\hline Stroke & 1.1 & 1.5 & 0.525 \\
\hline Mediastinitis & 0.4 & 2.7 & $<0.001$ \\
\hline Acute kidney injury & 30.7 & 49.4 & $<0.001$ \\
\hline Reintubation & 3.7 & 3.9 & 0.866 \\
\hline Return to operating room for bleeding & 3.2 & 4.3 & 0.395 \\
\hline New atrial fibrillation & 32.6 & 39.8 & 0.021 \\
\hline Leg wound infection & 0.7 & 1.2 & 0.463 \\
\hline Pneumonia & 1.7 & 0.8 & 0.275 \\
\hline
\end{tabular}

CABG: coronary artery bypass graft surgery; RBC: packed red blood cell transfusion; ICU: intensive care unit.

divided into predefined categories $(<6.0,6.0-7.9,8.0-9.9$, $10.0-12.0$, and $>12.0$ thousands per cubic millimeter, $\mathrm{mm}^{3}$ ).

Baseline, operative, and postoperative outcomes were compared using chi-square tests and continuous data using Student's $t$-test or Wilcoxon rank sum tests where appropriate. We conducted both univariate and backwards stepwise logistic regression removing risk factors that did not reach an alpha $<0.1$ among only risk factors with an alpha $<0.1$ from univariate comparisons. All risk factors meeting an alpha $<0.1$ were included in the final model multivariate logistic regression model. Categories of white blood cell counts were then added to the multivariate clinical risk prediction model. We conducted a Hosmer-Lemeshow goodness of fit test and calculated the area under the receiver operating characteristic (ROC) curve for the final multivariate model with categories of white blood cell count and reported the ROC and 95\% confidence intervals for each model. All analyses were performed using Stata 11.2 (College Station, TX).

\section{Results}

Among the 2,176 patients, 259 patients were readmitted within 30 days $(11.9 \%)$. The median time of readmission was 9 (IQR 4-16) days. Patient demographics were similar between patients with a 30 day readmission and those without a readmission. Patients readmitted within 30 days were more likely to have chronic obstructive pulmonary disease, 
TABLE 3: Univariate and multivariate regression anaylsis for 30-day readmission.

\begin{tabular}{lcc}
\hline & \multicolumn{2}{c}{ Odds ratios (95\% CI) for 30-day readmission } \\
& Univariate & Multivariate \\
\hline White blood cell count (in 1,000's, $\left.\mathrm{mm}^{3}\right)$ & Reference & $0.96(0.65,1.41)$ \\
$<6.0$ & $0.93(0.64,1.33)$ & $0.91(0.59,1.39)$ \\
$6.0-7.9$ & $0.86(0.58,1.29)$ & $1.42(0.86,2.34)$ \\
$8.0-9.9$ & $1.34(0.84,2.14)$ & $1.81(1.03,3.17)$ \\
$10.0-12.0$ & $1.73(1.03,2.93)$ & $1.73(1.24,2.43)$ \\
$>12.0$ & & $1.43(1.00,2.06)$ \\
Other risk factors & $1.77(1.28,2.46)$ & $1.85(0.98,3.52)$ \\
Single-vessel disease & $1.48(1.04,2.10)$ & $1.39(0.96,2.00)$ \\
Two-vessel disease & $2.43(1.31,4.54)$ & $1.52(1.07,2.18)$ \\
On-pump surgery & $1.55(1.10,2.17)$ & $5.81(1.87,18.08)$ \\
Nadir hematocrit on bypass $<20$ & $1.86(1.34,2.56)$ & $2.03(1.53,2.68)$ \\
Three or more packed red blood cells & $7.58(2.64,21.79)$ & \\
Mediastinitis & $2.21(1.70,2.87)$ & \\
Acute kidney injury & & $\chi^{2}=10.94, P$ value $=0.2$ \\
Model parameters & & 0.66 \\
Hosmer-Lemeshow $\chi^{2}, P$ value & & \\
ROC & & \\
\hline
\end{tabular}

WBC: white blood cell; SD: standard deviation of the log-transform of WBC count; ROC: area under the receiver operating characteristic curve.

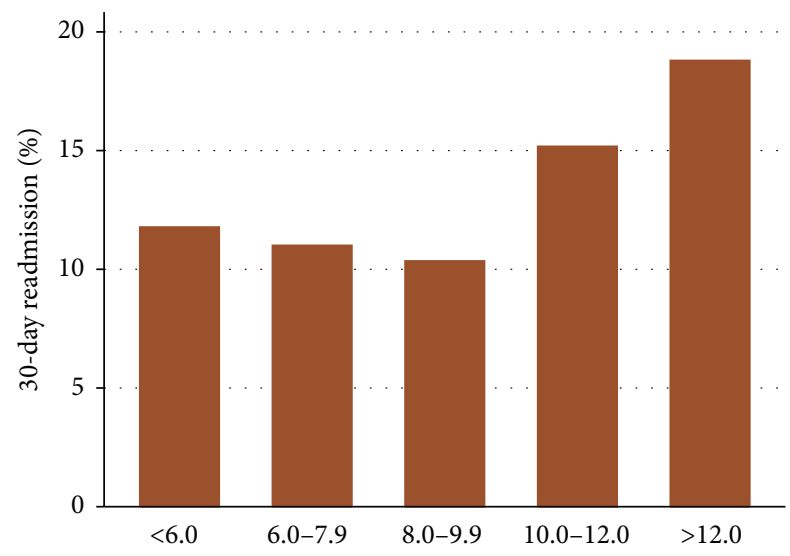

Figure 1: Preoperative White Blood Cell Counts and Risk of 30day Readmission. The graph plots the risk of all-cause 30-day readmission by five pre-defined categories of preoperative white blood cell counts (in thousands per cubic millimeter, $\mathrm{mm}^{3}$ ).

history of dialysis, single vessel coronary disease, and white blood cell counts greater than ten thousand prior to surgery (Table 1). Procedural factors associated with 30-day readmission included valve or combined CABG/valve procedure, on-pump surgery, nadir hematocrit $<20$ on bypass, three or more packed red blood cell transfusions, use of inotropes, and the development mediastinitis, AKI, or atrial fibrillation (Table 2).

Patients with elevated WBC counts at baseline (10,00012,000 and $>12,000 \mathrm{~mm}^{3}$ ) had higher 30-day readmission than those with lower WBC counts prior to surgery $(15 \%$ and $18 \%$ compared to $10 \%-12 \%, P=0.037$, Figure 1$)$. After backwards stepwise regression, WBC count and other risk factors remained significantly associated with 30-day readmission including number of diseased vessels, on-pump surgery, nadir hematocrit $<20$ on bypass, receiving three or more packed red blood cells, developing mediastinitis, and acute kidney injury (Table 3). Type of surgery (valve, isolated coronary artery bypass graft, or combined valve/graft) and duration of bypass were not significantly associated with readmissions in the multivariate model. Adjusting odds ratios for preoperative WBC counts were $1.42(0.86,2.34)$ for counts $10,000-12,000\left(\mathrm{~mm}^{3}\right)$ and $1.81(1.03,3.17)$ for counts $>12,000$ $\left(\mathrm{mm}^{3}\right)$ (Table 2$)$. The calculated c-statistic was 0.66 with a Hosmer-Lemeshow goodness of fit chi-square of 10.94 and $P$ value of 0.2 . Patient and procedural characteristics stratified by white blood cell categories are summarized in Table 4 .

\section{Discussion}

We explored the predictive ability of WBC counts prior to cardiac surgery on 30-day readmission. With and without adjustment of other risk factors for readmission, patients with preoperative WBC counts $>12,000\left(\mathrm{~mm}^{3}\right)$ were significantly more likely to be readmitted to the hospital within 30 days from discharge. We are the first to demonstrate that a marker of inflammation prior to the start of surgery demonstrates increased risk of 30-day readmission and should be incorporated into risk models to predict readmission prior to discharge from cardiac surgery.

WBC count has enjoyed a resurgence in recent years as a valid marker of inflammation and as a strong independent predictor of future coronary heart disease and stroke $[15,16]$. After an acute event, patient outcomes remain influenced by WBC count at the time of hospital admission. In several studies, peak WBC count or elevated monocyte count has been 
TABLE 4: Characteristics of patients and white blood cell count categories.

\begin{tabular}{|c|c|c|c|c|c|c|}
\hline \multirow{2}{*}{ Characteristic } & \multicolumn{6}{|c|}{ White blood cell count (in 1,000 s) } \\
\hline & $<6.0$ & $6.0-7.9$ & $8.0-9.9$ & $10.0-12.0$ & $>12.0$ & $P$ value \\
\hline Number of patients $(2,176)$ & 433 & 845 & 541 & 224 & 133 & \\
\hline \multicolumn{7}{|l|}{ Demographics } \\
\hline Age & $67.7 \pm 11.3$ & $67.1 \pm 10.6$ & $65.5 \pm 11.4$ & $63.6 \pm 11.7$ & $63.5 \pm 12.1$ & $<0.001$ \\
\hline Female & 30.3 & 29.5 & 26.6 & 31.7 & 27.8 & 0.594 \\
\hline BMI & $28.5 \pm 5.3$ & $29.6 \pm 6.0$ & $30.3 \pm 6.2$ & $30.3 \pm 6.1$ & $29.4 \pm 5.5$ & $<0.001$ \\
\hline \multicolumn{7}{|l|}{ Comorbidities } \\
\hline Type 2 diabetes mellitus & 26.3 & 31.6 & 36.8 & 32.6 & 34.6 & 0.014 \\
\hline Vascular disease & 25.6 & 27.9 & 27.9 & 29.9 & 28.6 & 0.817 \\
\hline COPD & 12.2 & 14.7 & 19.4 & 20.1 & 18.1 & 0.009 \\
\hline History of dialysis & 2.1 & 2.4 & 2.6 & 2.7 & 7.5 & 0.013 \\
\hline Smoking & 9.7 & 17.9 & 28.8 & 35.7 & 30.1 & $<0.001$ \\
\hline \multicolumn{7}{|l|}{ Cardiac history } \\
\hline Recent MI & 7.6 & 15.5 & 17.6 & 28.1 & 33.1 & $<0.001$ \\
\hline $\mathrm{CHF}$ & 18.7 & 18.7 & 21.4 & 22.3 & 30.8 & 0.017 \\
\hline Prior CABG & 5.1 & 3.9 & 3.1 & 1.8 & 4.5 & 0.256 \\
\hline Prior valve & 2.5 & 1.3 & 0.9 & 1.3 & 3.0 & 0.173 \\
\hline Prior PCI & 15.9 & 18.6 & 19.2 & 17.0 & 18.8 & 0.699 \\
\hline NYHA Class IV & 12.0 & 12.2 & 16.6 & 24.6 & 29.3 & $<0.001$ \\
\hline \multicolumn{7}{|l|}{ Cardiac anatomy and function } \\
\hline Left main disease $\geq 50 \%$ & 22.9 & 27.9 & 27.9 & 31.3 & 37.6 & 0.012 \\
\hline Single-vessel disease & 41.6 & 34.7 & 33.0 & 28.1 & 26.8 & 0.013 \\
\hline Two-vessel disease & 27.5 & 28.2 & 28.8 & 32.9 & 28.5 & \\
\hline Three-vessel disease & 30.9 & 37.2 & 38.2 & 39.1 & 44.7 & \\
\hline \multicolumn{7}{|l|}{ Ejection fraction } \\
\hline$<40 \%$ & 9.4 & 9.3 & 12.0 & 15.0 & 22.8 & $<0.001$ \\
\hline $40 \%-59 \%$ & 11.1 & 10.9 & 14.1 & 18.2 & 9.5 & \\
\hline $50 \%-59 \%$ & 25.9 & 24.2 & 24.1 & 21.5 & 26.0 & \\
\hline$\geq 60 \%$ & 53.5 & 55.5 & 49.8 & 45.3 & 41.7 & \\
\hline \multicolumn{7}{|l|}{ Procedural characteristics } \\
\hline \multicolumn{7}{|l|}{ Priority } \\
\hline Emergent & 1.6 & 2.8 & 6.1 & 10.3 & 23.3 & $<0.001$ \\
\hline Urgent & 46.0 & 47.9 & 51.2 & 61.2 & 60.9 & \\
\hline Elective & 52.4 & 49.2 & 42.7 & 28.6 & 15.8 & \\
\hline \multicolumn{7}{|l|}{ Procedure } \\
\hline CABG & 50.6 & 59.1 & 62.5 & 67.4 & 66.2 & $<0.001$ \\
\hline Valve & 31.4 & 23.7 & 21.3 & 15.2 & 16.5 & \\
\hline CABG/valve & 18.0 & 17.3 & 16.3 & 17.4 & 17.3 & \\
\hline On-pump surgery & 92.4 & 92.0 & 88.7 & 89.7 & 90.2 & 0.213 \\
\hline Nadir hematocrit $<20$ on bypass & 11.8 & 15.0 & 13.7 & 12.1 & 15.8 & 0.465 \\
\hline Cardiopulmonary bypass time (min) & $121.5 \pm 55.2$ & $117.1 \pm 49.2$ & $122.1 \pm 55.7$ & $121.4 \pm 62.2$ & $124.7 \pm 57.9$ & 0.656 \\
\hline Time to initial extubation (min) & $14.4 \pm 28.6$ & $15.6 \pm 32.7$ & $16.6 \pm 51.4$ & $20.8 \pm 51.8$ & $35.9 \pm 199.8$ & $<0.001$ \\
\hline Intraoperative myocardial infarction & 1.2 & 2.5 & 2.4 & 3.1 & 4.5 & 0.203 \\
\hline Return to bypass & 5.1 & 4.7 & 3.0 & 3.1 & 5.3 & 0.343 \\
\hline \multicolumn{7}{|l|}{ Management } \\
\hline RBC transfusion & 36.3 & 32.9 & 30.7 & 31.7 & 43.6 & 0.041 \\
\hline Use of 2 or more inotropes within 48 hours & 2.1 & 3.6 & 2.5 & 4.5 & 4.6 & 0.278 \\
\hline
\end{tabular}


TABLE 4: Continued.

\begin{tabular}{|c|c|c|c|c|c|c|}
\hline \multirow{2}{*}{ Characteristic } & \multicolumn{6}{|c|}{ White blood cell count (in 1,000s) } \\
\hline & $<6.0$ & $6.0-7.9$ & $8.0-9.9$ & $10.0-12.0$ & $>12.0$ & $P$ value \\
\hline \multicolumn{7}{|l|}{ Adverse outcomes } \\
\hline Low-cardiac output failure & 7.4 & 8.8 & 6.7 & 8.5 & 14.3 & 0.063 \\
\hline Stroke & 1.2 & 0.8 & 1.5 & 1.8 & 0.8 & 0.687 \\
\hline Mediastinitis & 0.2 & 0.7 & 0.6 & 0.9 & 1.5 & 0.552 \\
\hline Acute kidney injury & 29.3 & 33.6 & 31.4 & 37.5 & 38.4 & 0.128 \\
\hline Reintubation & 3.0 & 2.8 & 4.8 & 4.5 & 5.3 & 0.239 \\
\hline Return to operating room for bleeding & 6.0 & 3.1 & 1.9 & 2.2 & 4.5 & 0.005 \\
\hline New atrial fibrillation & 32.1 & 34.8 & 31.8 & 32.6 & 36.8 & 0.650 \\
\hline Leg wound infection & 0.7 & 0.8 & 0.7 & 1.3 & 0.0 & 0.731 \\
\hline Pneumonia & 1.6 & 1.4 & 1.1 & 3.1 & 1.5 & 0.354 \\
\hline
\end{tabular}

COPD: chronic obstructive pulmonary disease; MI: myocardial infarction; CHF: congestive heart failure; CABG: coronary artery bypass graft surgery; PCI: percutaneous coronary intervention; WBC: white blood cell; eGFR: estimated glomerular filtration rate; CABG: coronary artery bypass graft surgery; RBC: red blood cell; ICU: intensive care unit.

linked to death or major adverse cardiac events (MACEs) outcomes, including readmission [17-19]. Other strong evidence has linked high WBC count at admission with adverse outcomes (mortality and bleeding) in patients undergoing coronary revascularization with cardiopulmonary bypass [11, 12]. However, in the case of cardiopulmonary bypass it is unclear whether high WBC count contributes to preexisting risk or to development of the systemic inflammatory response postoperatively or both.

The systemic inflammatory response is a complication in cardiopulmonary bypass patients that is caused by a combination of surgical stress and contact activation of blood component in the extracorporeal circuit [20,21]. It is poorly defined [22] and the only formal definition is the Systemic Inflammatory Response Syndrome (SIRS), borrowed from the sepsis field [9]. According to the definition, SIRS exists when any two out of four criteria relating to abnormal temperature, heart rate, respiratory rate, or white cell counts exist. The upper threshold for abnormal white cell count according to the definition is 12,000 [9]. An evidence-based review of the inflammatory response indicated that all four SIRS criteria were rarely monitored in the setting of cardiopulmonary bypass [23] as they were felt to be too nonspecific [22] and if taken literally would apply to approximately $40 \%$ of all patients [24-26]. A more recent update on minimal reporting criteria by the Outcomes Consensus Panel singled out WBC count as the only criterion measured on its own as being relevant to the inflammatory status [10]. This recommendation was supported by other fields in which WBC count is recognized as a valid marker of inflammation $[5,6,8,27]$.

An alternative theory for the development of the systemic inflammatory response is that this is determined less by the extracorporeal circuit itself but rather by preexisting activation of white cells and endothelium [28] or by preoperative transfusion. Consistent with this theory is that high WBC count prior to coronary surgery utilizing cardiopulmonary bypass is linked with adverse outcomes including mortality and bleeding $[11,12]$. Our present findings that high WBC count before-surgery is linked to an increased risk of 30-day readmission after discharge add further weight to this idea.
We therefore conclude that WBC count measured prior to cardiac surgery may serve as a measure of the patient's inflammatory status and could aid in identifying and managing patients at heightened risk of readmission after discharge from cardiac surgery. This becomes especially relevant in an era when higher than expected readmission rates may attract financial penalties to hospitals.

\section{Conflict of Interests}

The authors declare no conflict of interests.

\section{Acknowledgments}

The authors thank and acknowledge those allied health professionals that contributed to the development of the data collection form for readmissions and conducting the chart reviews including Cathy Ross, David Malenka, Kristine Chaisson, Rick Boss, Robert Helm, Susan Horton, Patricia Hofmaster, Helen Desaulniers, Benjamin Westbrook, Dennis Duquette, Kelly LeBlond, Cheryl Jones, Reed Quinn, and Patrick Magnus. The Northern New England Cardiovascular Disease Study Group is with Dartmouth-Hitchcock Medical Center, Clinical Research, Rubin Building 5th Floor, One Medical Center Drive, Lebanon, NH, USA. The study was funded in part by the Northern New England Cardiovascular Disease Study Group. Dr. Brown is supported by Grant no. K01HS018443 from the Agency for Healthcare Research and Quality on Patient Safety and Acute Kidney Injury.

\section{References}

[1] S. F. Jencks, M. V. Williams, and E. A. Coleman, "Rehospitalizations among patients in the medicare fee-for-service program," The New England Journal of Medicine, vol. 360, no. 14, pp. 14181428, 2009.

[2] The Patient Protection and Affordability Care (PPAC) Act, Section 3025, 2011.

[3] J. Angelelli, D. Gifford, O. Intrator, P. Gozalo, L. Laliberte, and V. Mor, "Access to postacute nursing home care before and after the BBA," Health Affairs, vol. 21, no. 5, pp. 254-264, 2002. 
[4] Z. Li, E. J. Armstrong, J. P. Parker, B. Danielsen, and P. S. Romano, "Hospital variation in readmission after coronary artery bypass surgery in California," Circulation, vol. 5, no. 5, pp. 729-737, 2012.

[5] M. Madjid, I. Awan, J. T. Willerson, and S. W. Casscells, "Leukocyte count and coronary heart disease: implications for risk assessment," Journal of the American College of Cardiology, vol. 44, no. 10, pp. 1945-1956, 2004.

[6] J. Chen, R. P. Wildman, L. L. Hamm et al., "Association between inflammation and insulin resistance in U.S. nondiabetic adults: results from the Third National Health and Nutrition Examination Survey," Diabetes Care, vol. 27, no. 12, pp. 2960-2965, 2004.

[7] W. Q. Gan, S. F. P. Man, A. Senthilselvan, and D. D. Sin, "Association between chronic obstructive pulmonary disease and systemic inflammation: a systematic review and a meta-analysis," Thorax, vol. 59, no. 7, pp. 574-580, 2004.

[8] D. N. Reddan, P. S. Klassen, L. A. Szczech et al., "White blood cells as a novel mortality predictor in haemodialysis patients," Nephrology Dialysis Transplantation, vol. 18, no. 6, pp. 1167-1173, 2003.

[9] R. C. Bone, R. A. Balk, F. B. Cerra et al., "Definitions for sepsis and organ failure and guidelines for the use of innovative therapies in sepsis. The ACCP/SCCM Consensus Conference Committee. American College of Chest Physicians/Society of Critical Care Medicine," Chest, vol. 101, no. 6, pp. 1644-1655, 1992.

[10] R. C. Landis, J. M. Murkin, D. A. Stump et al., "Consensus statement: minimal criteria for reporting the systemic inflammatory response to cardiopulmonary bypass," Heart Surgery Forum, vol. 13, no. 2, pp. E116-E123, 2010.

[11] L. J. Dacey, J. DeSimone, J. H. Braxton et al., "Preoperative white blood cell count and mortality and morbidity after coronary artery bypass grafting," Annals of Thoracic Surgery, vol. 76, no. 3, pp. 760-764, 2003.

[12] R. Mehran, S. J. Pocock, E. Nikolsky et al., "A risk score to predict bleeding in patients with acute coronary syndromes," Journal of the American College of Cardiology, vol. 55, no. 23, pp. 25562566, 2010.

[13] J. Chung, M. A. Corriere, R. K. Veeraswamy et al., "Risk factors for late mortality after endovascular repair of the thoracic aorta," Journal of Vascular Surgery, vol. 52, no. 3, pp. 549-554, 2010.

[14] P. A. Linden, B. Y. Yeap, M. Y. Chang et al., "Morbidity of lung resection after prior lobectomy: results from the Veterans Affairs National Surgical Quality Improvement Program," Annals of Thoracic Surgery, vol. 83, no. 2, pp. 425-432, 2007.

[15] M. Madjid and O. Fatemi, "Components of the complete blood count as risk predictors for coronary heart disease: in-depth review and update," Texas Heart Institute Journal, vol. 40, no. 1, pp. 17-29, 2013.

[16] G. D. Friedman, A. L. Klatsky, and A. B. Siegelaub, "The leukocyte count as a predictor of myocardial infarction," The New England Journal of Medicine, vol. 290, no. 23, pp. 1275-1278, 1974.

[17] Y. Maekawa, T. Anzai, T. Yoshikawa et al., "Prognostic significance of peripheral monocytosis after reperfused acute myocardial infarction: a possible role for left ventricular remodeling," Journal of the American College of Cardiology, vol. 39, no. 2, pp. 241-246, 2002.

[18] Y. Gao, G.-X. Tong, X.-W. Zhang et al., "Interleukin-18 levels on admission are associated with mid-term adverse clinical events in patients with ST-segment elevation acute myocardial infarction undergoing percutaneous coronary intervention," International Heart Journal, vol. 51, no. 2, pp. 75-81, 2010.
[19] H. V. Barron, C. P. Cannon, S. A. Murphy, E. Braunwald, and C. M. Gibson, "Association between white blood cell count, epicardial blood flow, myocardial perfusion, and clinical outcomes in the setting of acute myocardial infarction: a thrombolysis in myocardial infarction 10 substudy," Circulation, vol. 102, no. 19, pp. 2329-2334, 2000.

[20] J. Butler, G. M. Rocker, and S. Westaby, "Inflammatory response to cardiopulmonary bypass," Annals of Thoracic Surgery, vol. 55, no. 2, pp. 552-559, 1993.

[21] R. C. Landis and R. J. de Silva, "The systemic inflammatory response to cardiopulmonary bypass," in Core Topics in Cardiac Anaesthesia, J. H. Mackay and J. E. Arrowsmith, Eds., Cambridge University Press, Cambridge, UK, 2012.

[22] K. M. Taylor, "SIRS-the systemic inflammatory response syndrome after cardiac operations," Annals of Thoracic Surgery, vol. 61, no. 6, pp. 1607-1608, 1996.

[23] R. C. Landis, J. R. Brown, J. M. Murkin, D. S. Likosky, and R. A. Baker, "An evidence based review of pharmaceutical interventions to limit the systemic inflammatory response in coronary surgery," Heart Surgery Forum, vol. 11, no. 5, pp. 1-12, 2008.

[24] G. Pilz, S. Kaab, E. Kreuzer, and K. Werdan, "Evaluation of definitions and parameters for sepsis assessment in patients after cardiac surgery," Infection, vol. 22, no. 1, pp. 8-17, 1994.

[25] F. Kerbaul, C. Guidon, P. J. Lejeune, M. Mollo, T. Mesana, and F. Gouin, "Hyperprocalcitonemia is related to noninfectious postoperative severe systemic inflammatory response syndrome associated with cardiovascular dysfunction after coronary artery bypass graft surgery," Journal of Cardiothoracic and Vascular Anesthesia, vol. 16, no. 1, pp. 47-53, 2002.

[26] M. Hensel, T. Volk, W. D. Döcke et al., "Hyperprocalcitonemia in patients with noninfectious SIRS and pulmonary dysfunction associated with cardiopulmonary bypass," Anesthesiology, vol. 89, no. 1, pp. 93-104, 1998.

[27] R. S. Carel and J. Eviatar, "Factors affecting leukocyte count in healthy adults," Preventive Medicine, vol. 14, no. 5, pp. 607-619, 1985.

[28] J. Litmathe, U. Boeken, G. Bohlen, D. Gursoy, C. Sucker, and P. Feindt, "Systemic inflammatory response syndrome after extracorporeal circulation: a predictive algorithm for the patient at risk," Hellenic Journal of Cardiology, vol. 52, no. 6, pp. 493-500, 2011. 


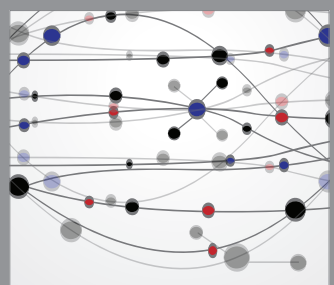

The Scientific World Journal
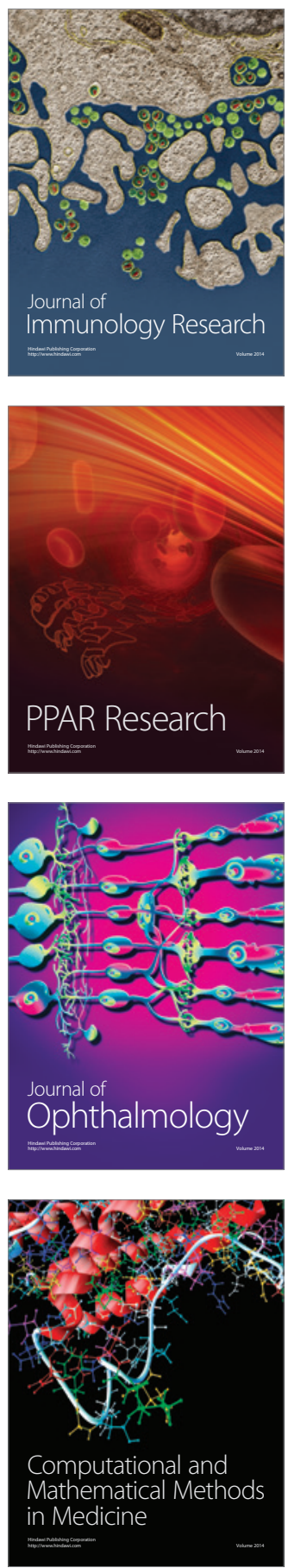

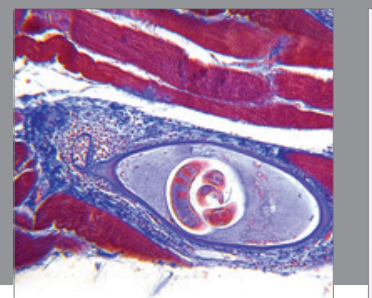

Gastroenterology

Research and Practice
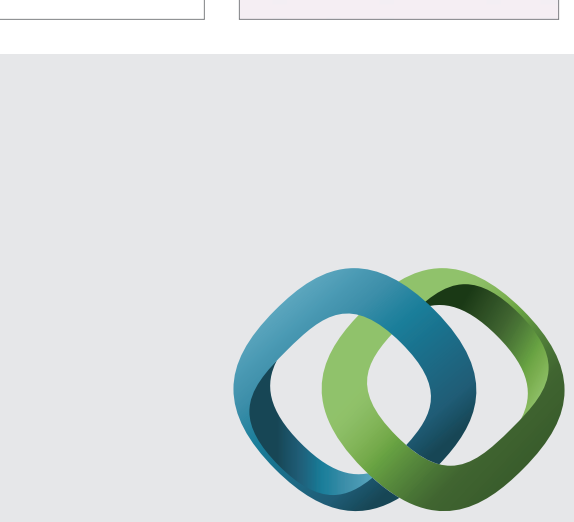

\section{Hindawi}

Submit your manuscripts at

http://www.hindawi.com
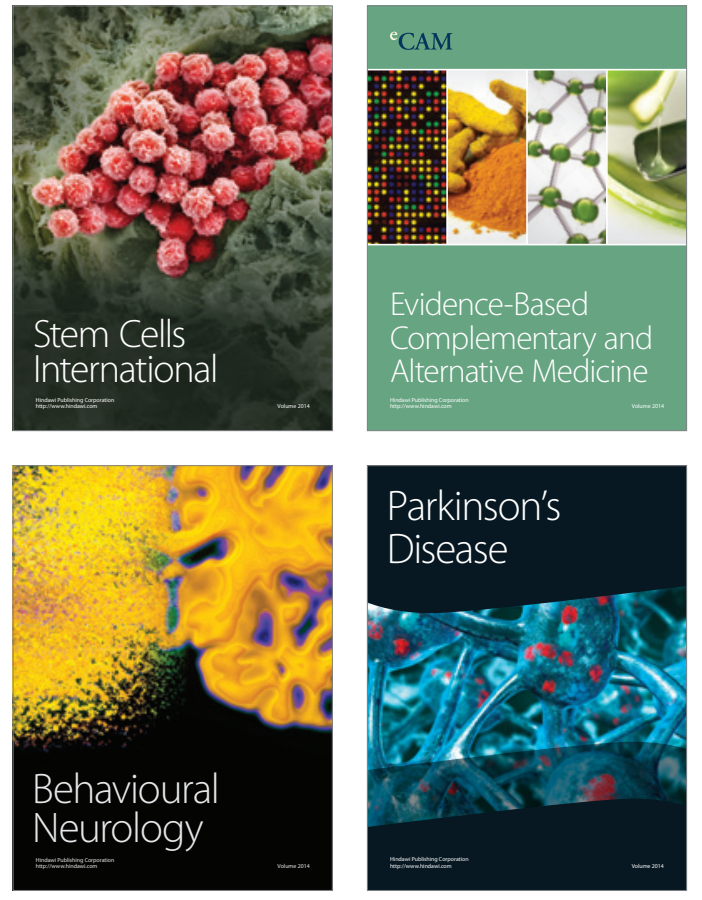
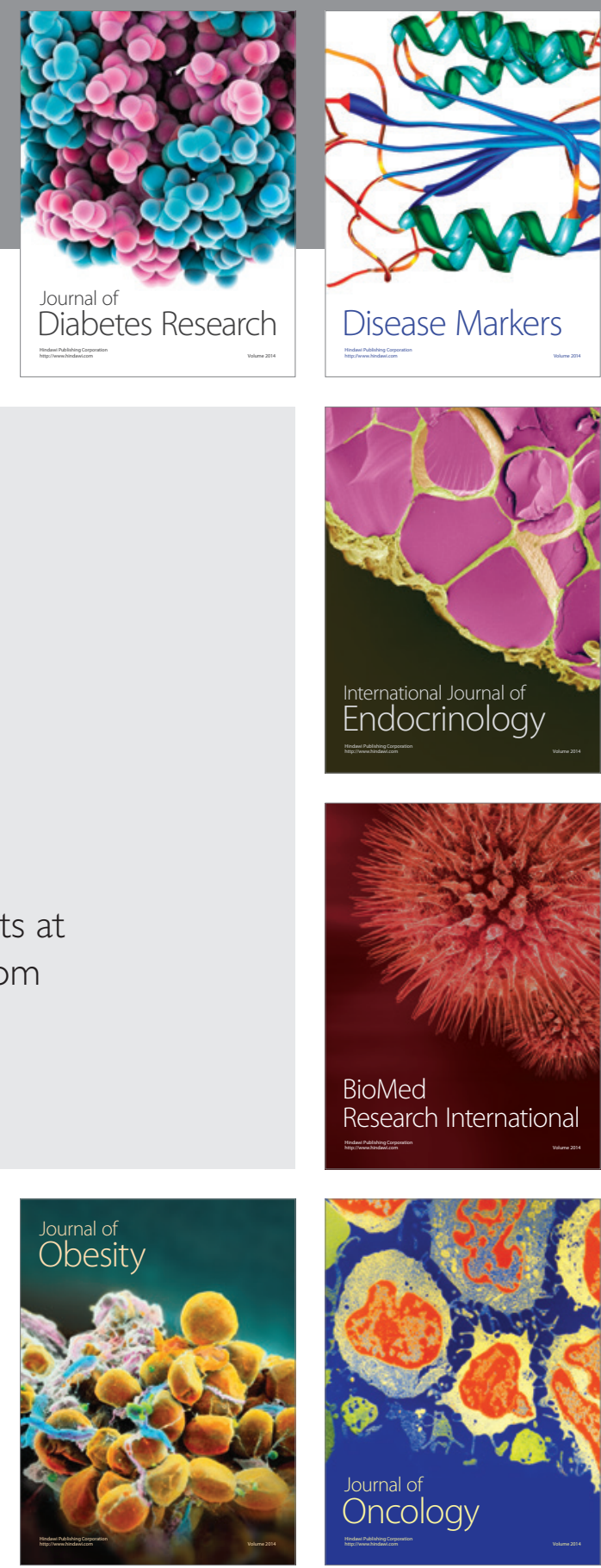

Disease Markers
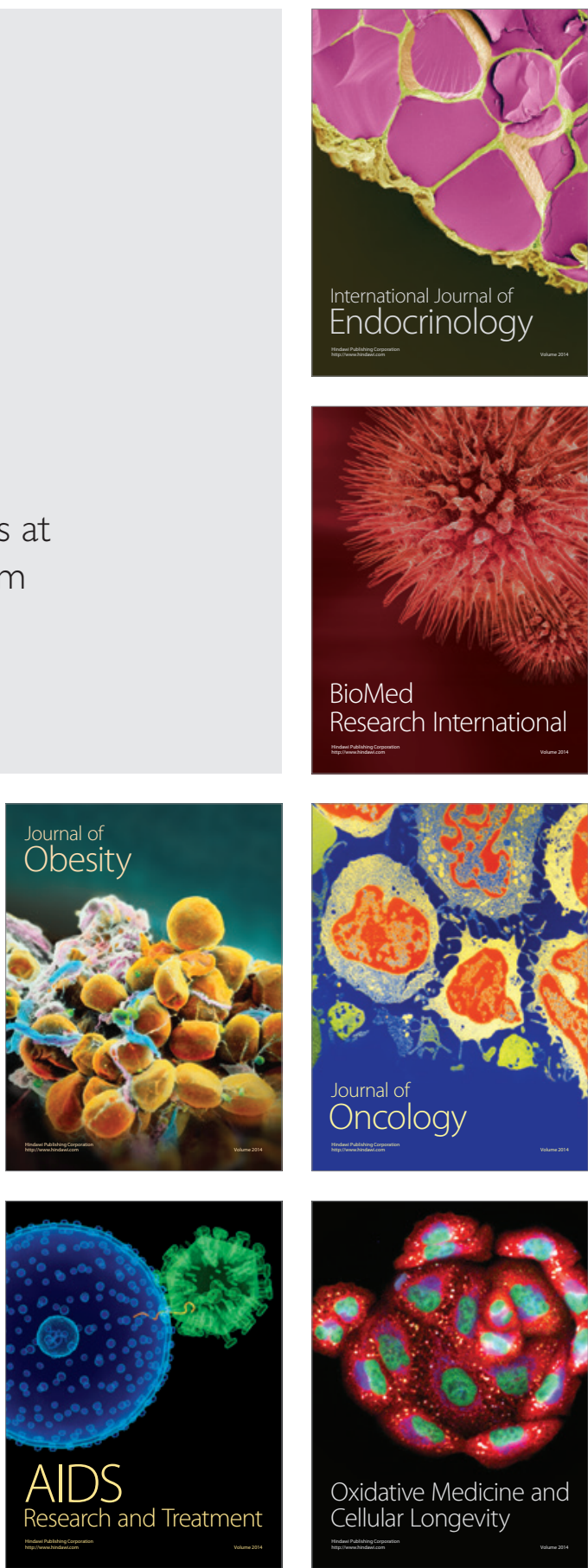